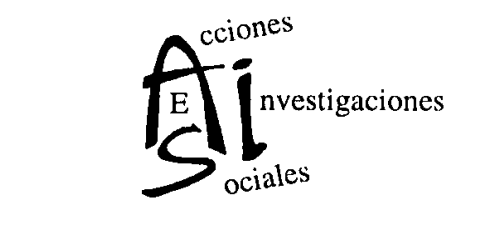

\title{
Guía de los principales ratios
}

\author{
Carlos Javier Sanz Santolaria \\ DEPARTAMENTO DE CONTABILIDAD Y FINANZAS \\ UNIVERSIDAD DE ZARAGOZA
}

El análisis contable trata de enjuiciar la situación de la empresa a partir de la información económico-financiera sometiéndola a diferentes estudios. Uno de los más importantes es el que se realiza mediante los ratios, que constituyen la forma más tradicional de análisis de estados contables.

Palabras clave: Estructura, Análisis, Ratio. 


\section{Guía de los principales ratios}

Carlos Javier Sanz Santolaria

\section{Introducción al análisis de los estados financieros}

El análisis de los estados financieros enjuicia la situación de la empresa a través de la información contable y otras fuentes de información, mediante la aplicación de técnicas o determinados instrumentos de análisis.

Si se trata de un usuario interno, se podrá acceder a toda la información de la unidad económica, por lo que sus estados contables serán analizados de una forma más detallada y precisa que si es un usuario externo.

Básicamente, el análisis contable pretende los siguientes objetivos:

1. Conocer la situación patrimonial, económica y financiera de la empresa.

2. Determinar las causas que han provocado la situación actual.

3. Aconsejar líneas de actuación de cara a una posible situación de desequilibrio.

4. Predecir, dentro de unos límites razonables, la evolución futura de la empresa.

El interés de la información es diferente según el objetivo o quién la interpreta, igualmente las técnicas utilizadas son distintas en cada uno de los casos. Si nos fijamos en los usuarios de la información contable, existen dos grupos diferenciados:

1. Capaces de influir en la elaboración: tienen fácil acceso a la información, pero los objetivos del análisis van a ser distintos. Los principales son: 
- Directivos: su objetivo es controlar la marcha de la empresa, comparar las metas previstas con los logros alcanzados, estudiando para las posibles desviaciones sus causas y soluciones.

- Propietarios: estudian los desequilibrios, así como los resultados y rentabilidad de la empresa, tanto actuales como futuros.

- Auditores: verifican la información y miden la solvencia de la empresa y de sus clientes.

- Administración fiscal:posee influencia de los requisitos fiscales sobre la empresa a la hora de adoptar determinados criterios.

2. No capaces de influir en la elaboración. Los principales son:

- Accionistas: entendidos como aquellos que no tienen ninguna vinculación con el consejo rector, estudian el equilibrio de la estructura de la empresa, la rentabilidad obtenida y las posibles evoluciones.

- Prestamistas: pretenden conocer el nivel de endeudamiento y grado de diversificación, capacidad de la empresa para afrontar las deudas y generar beneficios y tesorería.

- Trabajadores: les interesa conocer el valor añadido o rentas generadas de las que son partícipes, así como la seguridad de sus remuneraciones y estabilidad en el empleo.

Por su parte, el analista utiliza diferentes fuentes de información para realizar el análisis de la empresa, las más importantes son:

1. Cuentas anuales:

- Balance.

- Cuenta de Pérdidas y Ganancias.

- La memoria.

2. Estados complementarios y obligatorios (en algunos casos):

- Informe de gestión.

- Informe de auditoría.

3. Otros estados contables complementarios:

- Estado de valor añadido. 
- Estado de flujos de tesorería.

- Cuadro de financiación.

- Estado de variación del neto.

Este conjunto de estados contables presentan determinadas insuficiencias, como:

1. El análisis contable es efectuado por personas que, a veces, tienen intereses diferentes, por lo que los resultados no siempre son coincidentes.

2. Los estados contables presentan un formato definido, que por su estructura, no siempre están preparados para ser analizados directamente.

3. En los estados contables no se refleja habitualmente el efecto de la inflación.

4. Los estados contables recogen datos históricos, presentando limitaciones para las previsiones futuras.

Las soluciones que se apuntan para paliar dichas insuficiencias son:

1. Exigir información auditada para garantizar la veracidad de la información.

2. Solicitar información que corrija los efectos de la inflación. Actualmente, en España se efectúa a través de la Actualización de Balances.

3. Analizar información complementaria al balance y cuenta de pérdidas y ganancias.

4. Realizar un análisis estático y dinámico de la empresa.

El análisis contable se concreta en tres áreas de actuación:

1. Análisis patrimonial: estudia la evolución y tendencia de los principales elementos y masas patrimoniales pertenecientes a las estructuras económica y financiera, así como las correlaciones existentes entre las mismas.

2. Análisis financiero: tiene como finalidad el estudio de los recursos financieros, tratando de evaluar su grado de adecuación a las inversiones, así como evaluar la capacidad futura de la empresa para hacer frente a sus deudas.

3. Análisis económico:pretende medir la capacidad de la empresa para remunerar a los diversos agentes que participan en la misma, estudiar su evolución a lo largo del tiempo e 
intentar predecir el futuro, al mismo tiempo que se evalúa si dicho resultado es adecuado a los recursos aplicados para su obtención. Este análisis es eminentemente dinámico, y se basa en la cuenta de pérdidas y ganancias.

\section{Principales ratios utilizados en el análisis contable}

Los ratios constituyen la forma más tradicional de análisis de estados contables. Equivale a razón, índice, cociente o relación existente entre dos cuentas, masas o magnitudes determinadas.

Lógicamente, los elementos que son objeto de comparación han de tener alguna relación económica entre sí, porque en caso contrario el ratio no tendría ninguna significación.El listado o guía de los ratios más significativos utilizados en el análisis contable son:

\subsection{Ratios patrimoniales}

- Ratio de participación del activo fijo en el activo total:

$$
\frac{\text { Activo fijo }}{\text { Activo total }}
$$

- Ratio de participación del activo fijo en el activo circulante o también llamado «tasa de inversión»:

$$
\frac{\text { Activo fijo }}{\text { Activo circulante }}
$$

- Ratio de crecimiento o expansión del inmovilizado en un período de tiempo determinado:

$\frac{\text { Inmovilizado final - Inmovilizado inicial }}{\text { Inmovilizado inicial }}$

- Ratio de participación del activo circulante en el activo total:

$$
\frac{\text { Activo circulante }}{\text { Activo total }}
$$

- Ratio de crecimiento o expansión del activo circulante en un período de tiempo determinado: 
Activo circulante final - Activo circulante inicial

Activo circulante inicial

- Ratio o coeficiente de endeudamiento total:

Exigible total

Recursos propios

- Ratio de endeudamiento a corto plazo:

Exigible a corto plazo

Recursos propios

- Ratio de endeudamiento a largo plazo:

Exigible a largo plazo

Recursos propios

- Ratio de autonomía o independencia financiera:

Recursos propios

Exigible total

- Ratio o factor de apalancamiento financiero:

Exigible total

Activo total

- Ratio o índice de productividad:

Producción (en unidades monetarias)

Activo fijo

- Ratio de financiación ajena del inmovilizado:

Exigible a largo plazo

Activo fijo

- Período medio de almacenamiento:

Inventario medio x 365

Consumo del período

- Período medio de cobro:

Saldo medio de clientes $\times 365$

Ventas netas

- Período medio de pago:

Saldo medio de proveedores $\times 365$

Compras netas 
2.2 Ratios financieros

- Ratio de liquidez general:

$$
\frac{\text { Activo circulante }}{\text { Exigible a corto plazo }}
$$

- Ratio de disponibilidad inmediata o de liquidez de primer grado:

$$
\frac{\text { Disponible }}{\text { Exigible inmediato }}
$$

- Ratio de disponibilidad ordinaria o de liquidez de segundo grado:

$$
\frac{\text { Disponible }}{\text { Exigible a corto plazo }}
$$

- Ratio de tesorería:

$$
\frac{\text { Disponible + Realizable }}{\text { Exigible a corto plazo }}
$$

- Ratio de solvencia o garantía:

$$
\frac{\text { Activo real }}{\text { Exigible total }}
$$

- Ratio de firmeza o consistencia:

$$
\frac{\text { Activo fijo }}{\text { Exigible a largo plazo }}
$$

- Ratio de estabilidad o coeficiente de inmovilización:

$$
\frac{\text { Activo fijo }}{\text { Recursos permanentes }}
$$

- Ratio básico de financiación:

Recursos permanentes

$$
\text { Activo fijo }
$$

- Ratio de composición de la deuda:

Exigible a corto plazo

Exigible a largo plazo

- Ratio de financiación del activo circulante: 
Exigible a corto plazo

Activo circulante

- Ratio de financiación del inmovilizado:

Recursos permanentes

Activo fijo

- Ratio de independencia financiera:

Recursos propios

Activo real

- Ratio de dependencia financiera:

Exigible total

Activo real

- Ratio de recursos generados:

Amortización del ejercicio + Beneficio

Neto patrimonial

2.3 Ratios financieros

- Rentabilidad económica:

Resultado de la explotación

Activo neto medio

- Rentabilidad financiera:

$$
\frac{\text { Beneficio neto }}{\text { Recursos propios }}
$$

- Rentabilidad de las ventas:

Resultado de la explotación

Ventas netas

- Rotación del activo:

Ventas netas

Activo neto

- Rotación del activo fijo:

Ventas netas

Activo fijo 
- Rotación del activo circulante:

$$
\frac{\text { Ventas netas }}{\text { Activo circulante }}
$$

- Ventas por empleado:

$$
\frac{\text { Ventas netas }}{\text { Número medio de empleados }}
$$

- Gastos de personal por empleado:

$$
\frac{\text { Gastos de personal }}{\text { Número medio de empleados }}
$$

- Tipo medio de interés de la financiación ajena:

Gastos financieros

$$
\text { Exigible total }
$$

- Beneficio por acción o «earning per share»:

Beneficio neto

Número medio de acciones ordinarias

- Ratio de distribución de beneficio o «pay-out»:

Dividendos activos

$$
\text { Beneficio neto }
$$

- PER o «price earning ratio»:

Valor de cotización de la acción (price)

Beneficio por acción (earning)

- Rentabilidad financiera para el accionista:

Dividendo repartido

Valor bursátil de la acción

\section{Bibliografía}

ÁLVAREZ LÓPEZ, J.: Análisis de balances. Auditoría, agrega ción e interpretación. Donostiarra. San Sebastián, 1990.

ÁLVAREZ MELCÓN, S.: Análisis contable superior. UNED. Madrid, 1984. 
AMAT SALAS, O.: Análisis de estados financieros. Fundamentos y aplicaciones. Gestión 2000. Barcelona, 1994.

BERNSTEIN, L.A.: Análisis de estados financieros. Teoría, apli cación e interpretación. Ediciones S. Barcelona, 1993.

CARDONA LABARGA, J.M.: Análisis financiero. Ediciones Índex. Madrid, 1989.

CARMONA, S y CARRASCO, F.: Estados contables. McGrawHill. Madrid, 1994.

CHOLVIS, F.: Análisis e interpretación de estados contables. Ateneo. Buenos Aires, 1983.

ESTEO SÁNCHEZ, F.: Análisis de estados financieros. Planificación y control. Centro de Estudios Financieros. Madrid, 1995.

FERNÁNDEZ ELÉJAGA, J.A.: ¿Cómo interpretar un balance? Deusto. Bilbao, 1989.

FERNÁNDEZ PEÑA, E.: Formulación y análisis de estados con tables. Madrid, 1977.

FLORES CABALLERO, M.: El análisis de la rentabilidad. Técnica Contable, no 512-513. Madrid, agosto-septiembre, 1991.

GABÁS TRIGO, F.: Técnicas actuales de análisis contable. Evaluación de la solvencia empresarial. ICAC. Madrid, 1991.

GALLIZO LARRAZ, J.L.: Los estados financieros complementa rios del Plan General de Contabilidad. Pirámide. Madrid, 1993.

GARCÍA MARTÍN, V.: Solvencia y rentabilidad de la empresa española. Instituto de Estudios Económicos. Madrid, 1992.

GONZÁLEZPASCUAL, J.: Análisis de la empresa a través de su información económico-financiera. Pirámide. Madrid, 1995.

HALLER, L.: ¿Cómo comprender y utilizar la información conta ble? Deusto. Bilbao, 1987.

IGLESIAS SÁNCHEZ, J.L.: Insuficiencia de las cuentas anuales para reflejar la realidad económica.. Técnica Contable, no 517. Madrid, enero, 1992.

LEV, B.: Análisis de estados financieros:un nuevo enfoque. Esic. Madrid, 1978.

MAÑOSA, A.: Manual para la confección de análisis de balan ces. Gestión 2000. Barcelona, 1993.

MARTÍNEZ ARIAS, A.: Análisis económico-contable de la ges tión empresarial. ICAC. Madrid, 1988. 
PIZARRO, T.M.y ALFONSO, J.L.: Presentación y análisis de es tados contables. Ciencias Sociales. Madrid, 1991.

RIVERO ROMERO, J.: Un ensayo. Análisis de estados financie ros.Trivium. Madrid, 1991.

RIVERO ROMERO, J. y RIVERO MENÉNDEZ, Mà.J.: Análisis de estados financieros. Trivium. Madrid, 1992.

RIVERO TORRE, P.: Análisis de balances y estados comple mentarios. Pirámide. Madrid, 1991.

ROCAFORT NICOLAU, A.: Análisis e integración de balances. Hispano-Europea. Barcelona, 1983.

URÍAS VALIENTE, J.: Análisis de estados financieros. McGrawHill. Madrid, 1996.

URQUIJO DE LA FUENTE, J.L.: Análisis para decisiones finan cieras. Análisis y estados financieros. Deusto. Bilbao, 1990. WESTWICK, C.A.: Manual para la aplicación de ratios. Deusto. Bilbao, 1986.

WOELFEL, Ch.J.: Análisis de estados financieros. Ediciones S. Barcelona, 1993. 